\title{
ASSESSING THE ASSOCIATIONS BETWEEN TYPES OF GREEN SPACE, PHYSICAL ACTIVITY, AND HEALTH INDICATORS USING GIS AND PARTICIPATORY SURVEY
}

\author{
A. Akpinar ${ }^{\mathrm{a}, *}$ \\ ${ }^{a}$ Department of Landscape Architecture, Faculty of Agriculture, Adnan Menderes University, Aydin, Turkey, \\ abdullah.akpinar@wsu.edu
}

KEY WORDS: Green Space Types, Physical Activity, General Health, Quality of Life, Cardiovascular Disease, GIS

\begin{abstract}
:
This study explores whether specific types of green spaces (i.e. urban green spaces, forests, agricultural lands, rangelands, and wetlands) are associated with physical activity, quality of life, and cardiovascular disease prevalence. A sample of 8,976 respondents from the Behavioral Risk Factor Surveillance System, conducted in 2006 in Washington State across 291 zip-codes, was analyzed. Measures included physical activity status, quality of life, and cardiovascular disease prevalence (i.e. heart attack, angina, and stroke). Percentage of green spaces was derived from the National Land Cover Dataset and measured with Geographical Information System. Multilevel regression analyses were conducted to analyze the data while controlling for age, sex, race, weight, marital status, occupation, income, education level, and zip-code population and socio-economic situation. Regression results reveal that no green space types were associated with physical activity, quality of life, and cardiovascular disease prevalence. On the other hand, the analysis shows that physical activity was associated with general health, quality of life, and cardiovascular disease prevalence. The findings suggest that other factors such as size, structure and distribution (sprawled or concentrated, large or small), quality, and characteristics of green space might be important in general health, quality of life, and cardiovascular disease prevalence rather than green space types. Therefore, further investigations are needed.
\end{abstract}

\section{INTRODUCTION}

Today, physical inactivity has become an important threat to human life. Therefore, the World Health Organization has identified physical inactivity as the fourth leading risk factor for global mortality (WHO, 2010). Studies indicate that serious health problems such as coronary heart disease, obesity, chronic diseases, type 2 diabetes, breast and colon cancers, psychological disorders, and shortens life expectancy are related to physical inactivity (Lee, et al., 2012; Sallis, et al., 2012; The Ministry of Health, 2014). As of 2012, 31.1\% of adults worldwide are reported to be physically inactive (Hallal, et al., 2012) and for the USA $33.2 \%$ of women and $29.9 \%$ of men are physically inactive (Go, et al., 2013).

Considering the prevalence and negative effects of physical inactivity on human health, more attention is required to increase the level of people's physical activity (PA). In order to do that, it is important to know and understand the factors that are related to PA (Schipperijn, et al., 2013; Koohsari, et al., 2015). One of the important factors that affects PA is green space (Akpinar, 2016; Koohsari, et al., 2015; Bedimo-Rung, et al., 2005; Kaczynski \& Henderson, 2007). Green spaces strongly affect nearby inhabitants' well-being, behavior, and health and address human needs (Niemelä, et al., 2011; Schipperijn, et al., 2010; Matsuoka \& Kaplan, 2008) as well as physiological and psychological health (Morita, et al., 2007; Pretty, et al., 2007; Herzog \& Strevey, 2008; Ward Thompson, 2011). Green spaces create important opportunities for people to connect with nature, to exercise through involvement in both passive and active recreation, and to be involved in many kinds of social, cultural and community activities (Dunnett, et al., 2002; Orr, et al., 2014). A growing body of research suggests that green spaces are related to people's level of PA (Akpinar, 2016; Schipperijn, et al., 2013; Amorim, et al., 2010; Kaczynski, et al., 2009; Cohen, et al.,
2007). Research shows that nearest distance to green spaces is positively related to higher levels of PA (Cohen, et al., 2007; Kaczynski, et al., 2009; Toftager, et al., 2011; Akpinar, 2016) and frequency of green spaces use (Cohen, et al., 2007; Mowen, et al., 2007; Schipperijn, et al., 2010; Akpinar, 2014, 2016). Positive associations between higher level of PA and size of green spaces are also found (Kaczynski, et al., 2008; Sugiyama, et al., 2010; Paquet, et al., 2013; Akpinar, 2016).

PA contribution to human health is well documented. PA has been shown to improve general health (Akpinar, 2016; De Jong, et al., 2012; Bize, et al., 2007), well-being (Hansmann, et al., 2007), and mood (Rethorst, et al., 2009; Barton \& Pretty, 2010). PA also has been found to reduce stress (Tsatsoulis \& Fountoulakis, 2006; Hamer, et al., 2009; Barton \& Pretty, 2010; Akpinar, 2016), mental health problems such as anxiety (Mackay \& Neill, 2010; Fox, 1999) and depression (US Department of Health and Human Services, 1996; Rethorst, et al., 2009), overweight (Shaw, et al., 2006; Nocon, et al., 2008), and the risk of cardiovascular disease (Tamosiunas, et al., 2014; Sallis, et al., 2012; Warburton, et al., 2006).

Some studies argue that PA in green environment might produce greater health benefits than PA elsewhere (Coon, et al., 2011; Mitchell, 2013). For instance, walking, jogging, running etc. in the presence of nature/green space which is called as "green exercise" lessen the risk of cardiovascular diseases (Tamosiunas, et al., 2014; Sallis, et al., 2012) and provides mental and health benefits by improving self-esteem and well-being and reducing tension-anxiety, depression-dejection, confusion-bewilderment, and anger-hostality (Pretty, et al., 2007; Barton \& Pretty, 2010; Mackay \& Neill, 2010).

\footnotetext{
* Corresponding author
} 
Some of the studies, on the other hand, highlighted that it should not be presumed that all green space types are relevant across the whole spectrum of human benefits (Jorgensen \& Gobster, 2010). Van den Berg, et al., (2007), for instance, emphasized that little is known about the relationship between types of green space and health benefits. Richardson, et al., (2012) and Akpinar, et al. (2016) also recommended that future studies should focus on trying to distinguish types of 'green' in terms of health outcomes. Similarly, in Lee \& Maheswaran (2010)'s review, it is revealed that more research is required to establish and quantify the contribution of the different types of green spaces to health and PA. For that reason, some studies have begun investigating the relationship between different types of green space, PA, and health benefits and found that formal parks is significantly related to better PA and less overweight (Coombes, et al., 2010). Another study conducted by Picavet, et al. (2016) investigated the crosssectional and longitudinal associations between types of green space and PA. The study did not find any significant association between aggregated green space (i.e. urban green space, agricultural green, forest, and natural areas) and health. Picavet, et al. (2016), on the other hand, found that more urban green space was associated with more PA (i.e. sports and bicycling), whereas more agriculture green was associated with less PA. Studies concluded that more research is needed to better understand what types and features of green space might encourage people's PA. And, impact of different types of green space on PA has yet to be clarified (Coon, et al., 2011; Picavet, et al., 2016).

In this respect, this study aimed to provide new evidence on the associations between types of green space and PA and health indicators (i.e., quality of life (QoL), general health $(\mathrm{GH})$, and cardiovascular disease prevalence (CVD)) by combining information from the Behavioral Risk Factor Survey (BRFSS) and the National Land Cover Dataset (NLCD).

\section{METHODS}

\subsection{The Survey}

This study analyzed data from the BFRSS which is a telephone survey that is conducted by health departments of states with technical and methodological support of the Centers for Disease Control and Prevention (CDC) to assess the health practices and distribution of risk behaviors among non-institutionalized adults (CDC, 2006; Mokdad, 2009). The BRFSS includes information on residents' GH status, health related QoL, PA, CVD prevalence (i.e., heath attack, angina, and stroke), and demographics. The health data employed in this study from the BRFSS were:

1. General health status measured by the question "Would you say that in general your health is $1=$ Excellent, $2=$ Very good, $3=$ Good, 4= Fair, 5= Poor?"

2. Quality of life measured by the questions which could range from 0 to 30 days were;

a) Now thinking about your physical health, which includes physical illness and injury, for how many days during the past 30 days was your physical health not good?

b) Now thinking about your mental health, which includes stress, depression, and problems with emotions, for how many days during the past 30 days was your mental health not good?

c) During the past 30 days, for about how many days did poor physical or mental health keep you from doing your usual activities, such as self-care, work, or recreation?
3. Physical activity measured by the question was "During the past month, other than your regular job, did you participate in any physical activities or exercise such as running, calisthenics, golf, gardening, or walking for exercise?"

4. Cardiovascular disease prevalence measured by the questions were:

a) Has a doctor, nurse, or other health professional EVER told you that you had a heart attack, also called a myocardial infarction?

b) (Ever told) you had angina or coronary heart disease?

c) (Ever told) you had a stroke?

The BRFSS data contained responses coded to the US postal zipcode of the respondent's residence somewhere within the zipcode. The original dataset contained 23,760 responses in 668 zipcodes. The BRFSS data was processed to include only valid zipcodes for which there exist geographic (polygonal) boundaries. Thus, zip-codes that represented point locations such as Post Office Boxes and private companies where respondents clearly do not reside were excluded from the BRFSS dataset. The GIS zip-code dataset contained 532 zip-codes. Those zip-codes were matched to the BRFSS data. Non-matching zip-codes were also excluded, yielding 509 zip-codes. Cases coded as Don` t know/not sure, Refused or Missing for zip-codes as well as for the needed health and mental variables were also excluded (listwise deletion). This exclusion resulted in 9864 complete responses (41.52\% of total responses), distributed in 500 zip-codes.

To maximize external validity, zip-codes with fewer than 10 responses were excluded. This last exclusion yielded 8,976 complete responses distributed across 291 zip-codes which vary in size (minimum $=0.46 \mathrm{sq}$. $\mathrm{mi}$, maximum $=1,422.95 \mathrm{sq} . \mathrm{mi}, \mathrm{M}$ $=160.32$ sq. mi.), population ( minimum $=275$ people, maximum $=64,214$ people, $\mathrm{M}=22,018$ people), population density $($ minimum $=2.55$ people per sq. $\mathrm{mi}$, maximum $=17,894.56$ people per sq. mi, $\mathrm{M}=1,556.56$ people per sq. mi.), household income (minimum $=\$ 22,418$, maximum $=\$ 177,455$, medium $=$ $\$ 41,891$ ), unemployment (minimum $=1.41 \%$, maximum $=$ $45.71 \%, \mathrm{M}=7.01 \%$ ), and education level (i.e. bachelor degree or above) (minimum $=1.12 \%$, maximum $=95.83 \%, \mathrm{M}=$ $20.14 \%$ ). The exclusion of those zip-codes with fewer than 10 respondents did not alter the substantive results.

\subsection{Green Space Data}

The green space data was derived from the NLCD 2006 data, which contains the dominant type of land cover for each $30 \times 30$ $\mathrm{m}$ grid cell area in Washington State (USGS, 2012). Land cover classes in the NLCD 2006 were reclassified into five types of green space (i.e. urban green space, forest, rangeland, agricultural land, and wetland) (see Table 1). Among the NLCD 2006 Land Cover classes, only urban green space is not comprehensively identified; rather the NLCD 2006 identifies four classes of land use (i.e. developed-open space, developed-low intensity, developed-medium intensity, and developed-high intensity) in which built-on land is mixed with natural vegetation. These four classes are distinguished by the percentage of impervious land (i.e., pavement, asphalt, etc.) in the cell. For the urban green space category, the developed-open space and developed-low intensity classes where impervious surfaces account for less than $20 \%$ and $20 \%$ to $49 \%$ of total cover respectively were included. Based on the Forman`s (2008) definition of green space and similar work in the Netherlands (van Den Berg, et al., 2010) the developed-medium intensity and developed-high intensity classes where impervious surfaces account for $50 \%$ to $79 \%$ and $80 \%$ to $100 \%$ of total cover respectively were omitted due to 
large amount of impervious surfaces. Examples of the land uses included in the selected urban categories include large-lot singlefamily housing units, parks, golf courses, and vegetation planted in developed settings for recreation, erosion control, or aesthetic purposes (Fry, et al., 2011).

\begin{tabular}{|l|c|}
\hline The NLCD Code & Reclassification \\
\hline 21: Developed Open Space & Urban Green Space \\
22: Developed Low Intensity & \\
\hline 41: Deciduous Forest & Forest \\
42: Evergreen Forest & \\
43: Mixed Forest & Rangeland \\
\hline $\begin{array}{l}\text { 52: Shrub/Scrub } \\
\text { 71: Grasslands/Herbaceous }\end{array}$ & Agricultural Land \\
\hline $\begin{array}{l}\text { 81: Pasture/Hay } \\
\text { 82: Cultivated Crops }\end{array}$ & Wetland \\
\hline $\begin{array}{l}\text { 90: Woody Wetland } \\
\text { 95: Emergent Herbaceous Wetland }\end{array}$ & \\
\hline
\end{tabular}

Table 1. NLCD Green space variables.

Table 1 above lists the available land cover categories relevant to green space. To calculate the percentage of green space, the NLCD 2006 categories were reclassified as needed to obtain the green space categories given in Table 1, resulting in five greenspace types for each zip-code area. The proportion (normalized amount) of each type of green space in each zip-code was also calculated using this reclassified data. These values represent the total proportion of a green space type within a zip-code area.

\subsection{Socio-economic and Demographic Characteristics}

Because health may differ according to people's background characteristics, gender, age (in years), race, level of education, occupation, and household income of each respondent. Income level was categorized from less than $\$ 10,000$ to $\$ 75,000$ or more. Level of education was categorized from never attended school or only attended kindergarten to college 4 years or more (College graduate.) The potential for zip-code level confounding variables that might affect the associations were also concerned. Therefore, data at the zip-code level describing population, size (sq. mi), population density, socio-economic status (SES) (i.e. median household income, occupation (unemployment rate), and education level (bachelor's degree or higher)) were obtained from U. S. Census 2000 data.

\subsection{Analytic Strategy}

Preliminary analyses examined the normality of the variables. The responses to the GH question were normally distributed. To help clarify the relationship between QoL and green space, three questions were reduced to one factor using maximum likelihood exploratory factor analysis. The factor analysis was used because these questions together were intended to measure the level of QoL. Each question asked a different indicator of QoL so that they should be considered together. Then, the normality of QoL, $\mathrm{PA}$, and CVD prevalence were examined. Because the distributions of these variables were skewed, a $\log$ transformation $y=\log _{e}(x+1)$ to these three outcomes on which all test statistics are based were applied. However, the untransformed results were similar to those of the transformed data, and therefore the untransformed results were reported.

First, the relationships between types of green space and PA were analyzed while controlling for individual respondent characteristics at the individual level, and zip-code characteristics at the zip-code level via multilevel linear regression analyses. Prior to performing multilevel linear regression analyses, presence of multicollinearity issues between independent variables were checked. In this analysis, multicollinearity issues between population density and green space was found. Hence, population density from the regression model was excluded due to the multicollinearity issue.

Lastly, relationships between the five types of green space, PA and (i) GH, (ii) QoL, and (iii) CVD prevalence were examined with multilevel linear regression analyses while controlling for the possible confounding factors. A $p$-value of .05 was used to indicate statistical significance. SPSS version 18 was used for all statistical analyses.

\section{RESULTS}

\subsection{Sample Characteristics}

$34.47 \%$ of the BRFSS respondents were male and $65.53 \%$ were female while $55 \%$ of the respondents were married among the 8,976 participants. The average age of the participants was 50.55 years old. The highest participation age cohort in the BRFSS sample was ages 45 to $54(23.2 \%)$ and the lowest was ages 18 to $24(5.1 \%)$. The highest degree of education achieved by the respondents (college graduate or more) was $39.1 \%$. Regarding occupation, $46.6 \%$ of the respondents were employed while $2.1 \%$ were students. In terms of the total annual household income, $21.6 \%$ of the BRFSS respondents were in the highest income level (\$75,000 or more). Regarding race, the BRFSS sample was 90\% White.

\subsection{Health Responses and Green Space}

The mean of the $\mathrm{GH}$ was 2.72 while median was 3 ; the minimum response was 0 while the maximum was 5 . The mean of the QoL was 6.22 days and median was 2.67 day; the minimum response was 0 days while the maximum was 30 . For the CVD prevalence, $5.5 \%, 6.3 \%$, and $4 \%$ were diagnosed with hearth attack, heart disease, and stroke, respectively. In terms of PA, $78.8 \%$ of the respondents performed PA. Among all individuals, only $23.1 \%$ respondents rated their health in general as fair or poor. The descriptive statistics indicates that the data consists of selfreportedly healthy sample of individuals.

Regarding green space, the mean of percentage of urban green space in zip-codes was $24.93 \%$; the minimum percentage was $.33 \%$ while the maximum was $79.62 \%$. The mean of percentage of forest was $28.50 \%$; the minimum was $0 \%$ while the maximum was $93.20 \%$. For the rangeland, the mean of percentage was $16.65 \%$; the minimum was $0 \%$ while the maximum was $86.91 \%$. The mean of percentage of agricultural land was $11.19 \%$; the minimum percentage was $0 \%$ while the maximum was $87.83 \%$. Lastly, the mean of percentage of wetlands was $3.15 \%$; the minimum was $0 \%$ while the maximum was $39.61 \%$.

\subsection{The Associations between Types of Green Spaces and PA}

After controlling for the covariates, the multilevel regression analysis revealed that no types of green space are associated with PA (Table 2). The regression results indicated that those in a higher income $(\beta=.027, \mathrm{SE}=.003,95 \% \mathrm{CI} .022-.032)$ levels and those in higher education levels $(\beta=.046, \mathrm{SE}=.005,95 \% \mathrm{CI}$ $.036-.055)$ reported better PA whereas older adults $(\beta=-.003$, $\mathrm{SE}=.000,95 \% \mathrm{CI}-.004--.002)$, overweight people $(\beta=-.001$, $\mathrm{SE}=.000,95 \% \mathrm{CI}-.002-.001)$, and those who are unable to 
work $(\beta=-.148, \mathrm{SE}=.016,95 \% \mathrm{CI}-.180--.116)$ reported less PA. No other significant results were found.

\begin{tabular}{|c|c|c|}
\hline & \multicolumn{2}{|c|}{ Physical Activity } \\
\hline & $\beta$ & SE \\
\hline Sex (Male) & .017 & .009 \\
\hline Age & $-.003^{* * *}$ & .000 \\
\hline African American & -.060 & .038 \\
\hline Asian & -.005 & .034 \\
\hline Native Hawaiian or Other & -.001 & .079 \\
\hline $\begin{array}{l}\text { American Indian, Alaska } \\
\text { Native }\end{array}$ & .011 & .033 \\
\hline Other races & -.027 & .029 \\
\hline Multiracial & .010 & .023 \\
\hline Weight & $-.001^{* * * *}$ & .000 \\
\hline Divorced & -.022 & .013 \\
\hline Widowed & -.006 & .017 \\
\hline Separated & -.025 & .029 \\
\hline Never Married & .025 & .015 \\
\hline Unmarried Couple & .018 & .021 \\
\hline Education & $.0466^{* * * *}$ & .005 \\
\hline Self-Employed & .028 & .016 \\
\hline Out of Work (>1) & -.038 & .028 \\
\hline Out of Work $(1<)$ & .028 & .035 \\
\hline Homemaker & -.002 & .016 \\
\hline Student & .024 & .030 \\
\hline Retired & -.003 & .015 \\
\hline Unable to work & $-.148^{* * *}$ & .016 \\
\hline Income & $.027^{* * * *}$ & .003 \\
\hline Urban Green Space & .000 & .001 \\
\hline Forest & .000 & .000 \\
\hline Rangeland & .000 & .000 \\
\hline Agricultural Land & .000 & .000 \\
\hline Wetland & -.001 & .001 \\
\hline Zip-code Population & .001 & .000 \\
\hline Zip-code Size & .001 & .000 \\
\hline Zip-code Income & .001 & .000 \\
\hline Zip-code Unemployment & .000 & .001 \\
\hline Zip-code Education & .001 & .000 \\
\hline (College or more) & & \\
\hline $\mathrm{R}^{2}$ & $.115^{* * *}$ & \\
\hline
\end{tabular}

Table 2. The associations between types of green space and PA. Note: ${ }^{* * *} \mathrm{p} \leq .001,{ }^{* *} \mathrm{p} \leq .01,{ }^{*} \mathrm{p} \leq .05$, Women, White, Married, and Employed are the reference groups.

\subsection{The Associations between Green Spaces, PA, and Health Indicators}

As seen in Table 3, the multilevel regression results showed that no types of green space were associated with GH whereas PA was significantly associated with $\mathrm{GH}(\beta=-.363, \mathrm{SE}=.025,95 \%$ CI -.413 - -.313), where more PA was correlated with better GH. In terms of covariates, the findings revealed that those in a higher income $(\beta=-.098, \mathrm{SE}=.007,95 \% \mathrm{CI}-.111-.085)$ levels and those in higher education in both individual $(\beta=-.114, \mathrm{SE}=.011$, $95 \% \mathrm{CI}-.137--.032)$ and zip-code levels $(\beta=-.003, \mathrm{SE}=.001$,
95\% CI -.004 - -.001) reported better GH whereas older adults $(\beta=.013, \mathrm{SE}=.001,95 \% \mathrm{CI} .011-.014)$ and overweight people $(\beta=.004, \mathrm{SE}=.000,95 \% \mathrm{CI} .003-.005)$ reported poorer $\mathrm{GH}$. Among races, those who identify as Native Hawaiian or other Pacific Islander, American Indian/Alaska Native, multiracial, and other races reported poorer $\mathrm{GH}$ compared to White participants. In addition, those who were self-employed reported better GH while those who were out of work, homemaker, student, retired, and unable to work reported poorer GH compared to employed people.

For the QoL, the multilevel linear regression model showed that no types of green space were associated with QoL, whereas PA was significantly associated with $\mathrm{QoL}(\beta=-2.895, \mathrm{SE}=.164,95 \%$ CI -3.215 - -2.574) where more PA was correlated with better QoL. In terms of covariates, the results revealed that those in a higher income $(\beta=-.383, \mathrm{SE}=.043,95 \% \mathrm{CI}-.467-.299)$ levels and those in higher education levels $(\beta=-.446, \mathrm{SE}=.074,95 \% \mathrm{CI}$ $-.591--.302)$ reported better $\mathrm{QoL}$ whereas older adults $(\beta=.013$, $\mathrm{SE}=.006,95 \% \mathrm{CI} .002-.025)$ and overweight people $(\beta=.006$, $\mathrm{SE}=.002,95 \%$ CI .003 - .009) reported poorer QoL. Among races, those who identify as multiracial races reported poorer QoL compared to White participants. Those who were out of work, homemaker, retired, and unable to work reported poorer QoL compared to employed people. In addition, divorced and separated adults reported poorer QoL compared to married people.

\section{DISCUSSION}

The purpose of this study was to investigate the associations between types of green space and PA and health indicators (i.e., quality of life (QoL), general health $(\mathrm{GH})$, and cardiovascular disease prevalence (CVD)). The findings of this study that no type of green space was associated with PA and health indicators, which is unexpected considering the previous studies. On the other hand, the results revealed that PA was associated with health indicators. Several points are highlighted to explain the differences between this study and the previous studies.

First of all, the size of the study areas may be one of the reasons for the nonsignificant results. In previous studies, the relationship between green space and health was mostly examined either in a 1-3 km radius around participants' homes (de Vries et al., 2003; Maas et al., 2006; Van den Berg et al., 2010) or at the neighborhood level (Richardson et al., 2013; Beyer et al., 2014) while this study examined green space at the zip-code level which varies in size from 2.20 sq. mi to 1422.95 sq. mi. As previous studies indicated, distance, sometimes called proximity, is an important factor in the relationship between green space, PA, and health (Maas et al., 2009; Stigsdotter et al., 2010; Ward Thompson et al., 2012; Akpinar, 2016); hence, respondents may not have engaged with green space in large zip-codes when considered the size of zip-codes areas in this study. Therefore, possibly longer distances to green space may have also contributed to differences in results that the author did not find a significant association between types of green space, PA, and health indicators.

\begin{tabular}{|c|c|c|c|c|c|c|c|c|c|c|}
\hline & \multirow{2}{*}{\multicolumn{2}{|c|}{ General Health }} & \multirow{2}{*}{\multicolumn{2}{|c|}{ Quality of Life }} & \multicolumn{6}{|c|}{ Cardiovascular Disease Prevalence } \\
\hline & & & & & \multicolumn{2}{|c|}{ Hearth Attack } & \multicolumn{2}{|c|}{ Angina } & \multicolumn{2}{|c|}{ Stroke } \\
\hline & $\beta$ & SE & $\beta$ & SE & $\beta$ & SE & $\beta$ & SE & $\beta$ & SE \\
\hline Sex (Male) & .001 & .023 & -.237 & .146 & $.044^{* * * *}$ & .005 & $.034^{* * * *}$ & .006 & $.014^{* *}$ & .005 \\
\hline Age & $.013^{* * * *}$ & .001 & $.013^{* * * *}$ & .006 & $.002^{* * * *}$ & .000 & $002^{* * *}$ & .000 & $.001^{* * *}$ & .000 \\
\hline African American & .033 & .091 & -.360 & .588 & -.002 & .021 & -.001 & .023 & -.006 & .019 \\
\hline Asian & .148 & .082 & -.845 & .525 & -.008 & .019 & -.005 & .020 & -.001 & .017 \\
\hline Native Hawaiian or Pacific Islander & $.371^{*}$ & .190 & 2.261 & 1.222 & .065 & .044 & .061 & .047 & .029 & .039 \\
\hline
\end{tabular}




\begin{tabular}{|c|c|c|c|c|c|c|c|c|c|c|}
\hline American Indian, Alaska Native & $.213^{* *}$ & .080 & .820 & .515 & $.058^{* *}$ & 019 & $.046^{*}$ & .020 & .009 & 016 \\
\hline Other races & $.205^{* *}$ & .070 & -.310 & .453 & -.001 & .016 & -.004 & .018 & -.008 & .014 \\
\hline Multiracial & $.128^{*}$ & .055 & $1.938^{* * * *}$ & .351 & $.039^{* * * *}$ & .013 & $-.051^{* * *}$ & .023 & .020 & .011 \\
\hline Weight & $.004^{* * * *}$ & .000 & $006^{* * * *}$ & .002 & $.001^{*}$ & .000 & $.001^{* * * *}$ & .000 & -.001 & .000 \\
\hline Divorced & .012 & .030 & $.521^{* *}$ & .194 & -.011 & .007 & -.013 & .008 & .006 & .006 \\
\hline Widowed & -.072 & .041 & .203 & .262 & .013 & .010 & -.001 & .010 & $.026^{* *}$ & .008 \\
\hline Separated & .034 & .069 & $1.264^{* *}$ & .244 & -.009 & .016 & -.005 & .017 & .001 & .014 \\
\hline Never Married & .045 & .035 & -.119 & .015 & -.014 & .008 & -.005 & .009 & -.001 & .007 \\
\hline Unmarried Couple & .089 & .050 & .032 & .324 & -.006 & .012 & .002 & .013 & .001 & .010 \\
\hline Education & $-.114^{* *}$ & .011 & $-.446^{* * * *}$ & .074 & $-.009^{* *}$ & .003 & -.005 & .003 & $-.005^{*}$ & .002 \\
\hline Self-Employed & $-.116^{* *}$ & .038 & .199 & .243 & -.011 & .009 & -.002 & .009 & .002 & .008 \\
\hline Out of Work $(>1)$ & $.439^{* * * *}$ & .066 & $5.181^{* * * *}$ & .428 & -.011 & .016 & .002 & .017 & $.034^{*}$ & .014 \\
\hline Out of Work $(1<)$ & $.142^{* * * *}$ & .061 & $2.166^{* * * *}$ & .392 & .012 & .014 & .007 & .015 & -.005 & .012 \\
\hline Homemaker & $.120^{* *}$ & .039 & $.705^{* * *}$ & .252 & .009 & .009 & .007 & .010 & .010 & .008 \\
\hline Student & $.166^{*}$ & .072 & .556 & .465 & .020 & .017 & .033 & .018 & .011 & .015 \\
\hline Retired & $.253^{* * *}$ & .035 & $.872^{* * * *}$ & .015 & $.048^{* * * *}$ & .008 & $.067^{* * * *}$ & .009 & $.043^{* * * *}$ & .007 \\
\hline Unable to work & $.995^{* * * *}$ & .040 & $.863^{* * *}$ & .255 & $.056^{* * * *}$ & .009 & $.087^{* * * *}$ & .010 & $.064^{* * * *}$ & .008 \\
\hline Income & $-.098^{* *}$ & .007 & $-.383^{* * *}$ & .043 & $-.007^{* *}$ & .002 & $-.005^{* *}$ & .002 & $-.003^{*}$ & .001 \\
\hline Physical Activity & $-.363^{* *}$ & .025 & $-2.895^{* * *}$ & .164 & $-.024^{* *}$ & .006 & $-.018^{* * *}$ & .006 & $-.013^{*}$ & .005 \\
\hline Urban Green Space & .000 & .001 & -.005 & .008 & .000 & .000 & .000 & .000 & .000 & .000 \\
\hline Forest & -.001 & .001 & -.003 & .005 & .000 & .000 & -.001 & .000 & .000 & .000 \\
\hline Rangeland & -.002 & .001 & -.009 & .006 & .000 & .000 & .001 & .000 & .000 & .000 \\
\hline Agricultural Land & .001 & .001 & -.006 & .006 & -.001 & .000 & -.001 & .000 & .000 & .000 \\
\hline Wetland & .000 & .002 & -.006 & .016 & .001 & .001 & .001 & .001 & .000 & .000 \\
\hline Zip-code Population & .001 & .000 & -.001 & .000 & -.001 & .001 & .001 & .000 & .001 & .000 \\
\hline Zip-code Size & .001 & .000 & .000 & .000 & .001 & .000 & .001 & .000 & .001 & .000 \\
\hline Zip-code Income & -.001 & .000 & .001 & .000 & -.001 & .000 & -.001 & .000 & -.001 & .000 \\
\hline Zip-code Unemployment & .002 & .003 & .011 & .021 & -.001 & .001 & -.001 & .001 & .001 & .001 \\
\hline Zip-code Education (College or more) & -.003 & .001 & .005 & .006 & .001 & .000 & -.001 & .000 & -.001 & .000 \\
\hline $\mathrm{R}^{2}$ &. .31 $^{* * * *}$ & & $.320^{* * * *}$ & & $.095^{* * *}$ & & $.095^{* * *}$ & & $.060^{* * * *}$ & \\
\hline
\end{tabular}

Table 3. The associations between types of green space, PA, and health indicators.

Note: ${ }^{* * *} \mathrm{p} \leq .001,{ }^{* *} \mathrm{p} \leq .01,{ }^{*} \mathrm{p} \leq .05$, Women, White, Married, and Employed are the reference groups.

Distribution of green spaces (sprawled or concentrated, large or small) is another possible explanation of nonsignificant results. Previous studies showed that well-connected urban green spaces are associated with less mental health complaints, whereas people reported less mental health complaints and better general health with their environments when these environments consist of closed patches (Akpinar, 2015). Another study revealed that neighborhood satisfaction was high where the neighborhood environments were less fragmented, less isolated, and well connected (Lee, et al., 2008). The authors also found variety in the size and shape of tree patches also showed a positive relationship with neighborhood satisfaction. Therefore, distribution of types of green space may have affected the relationship with PA and health. In this respect, future studies need to investigate this possibility.

Another possibility is that as many studies emphasized, the quality rather than the quantity of green spaces may be important in the relationship between green space, PA, and health (Akpinar, 2016; Richardson et al., 2010; Richardson and Mitchell, 2010; Van den Berg et al., 2007; Maas et al., 2006; de Vries et al., 2003). Most of the previous studies suggested that those who live in relatively more abundant green space may have better mental and general health than those who live in less abundant green space conditions. However, this assumption is not supported by the findings of this study similarly to Picavet et al. (2016) and Richardson et al. (2012) studies. If "living in more abundant green" leads to better health, then the author should have found significant associations. However, no evidence were found in that direction. In this respect, quality over quantity of green space may be the reason for the nonsignificant results. Therefore, quality of green space should be investigated in the future studies.
Lastly, some studies found that some characteristics of green space are associated with PA (Akpinar \& Cankurt, 2016). It is important to note that, each type of green has different characteristics and human perception of landscapes is found to be associated with health and stress reduction (Ulrich, 1984; Ulrich et al., 1991), increased neighborhood satisfaction (Kaplan, 2001), and better restoration (Van den Berg et al., 2014). Hence, characteristics of types of green space may have contributed to nonsignificant results the author found. In this respect, future studies should investigate the characteristic of green space.

Despite the contribution this study has some limitations. The primary limitation is that the BRFSS does not provide respondents' exact locations within the zip-codes. Therefore, it was also not possible to know whether respondents engaged with green spaces or not. The cell size of the NLCD is another limitation in this study. The NLCD data is consist of $30 \mathrm{~m}$ cells, therefore the results did not include finer resolution details such as small-scale natural elements and areas like trees along streets, green road sides, or greenery were not explicitly represented in the study. Lastly, this research was a cross-sectional, therefore, causation cannot be implied.

\section{CONCLUSIONS}

This study investigated whether types of green space were associated with PA and health indicators. The findings showed no types of green space was associated with PA and health indicator. Based on the findings of this study and previous studies, four possibilities were emphasized: a) proximity to green space, b) structure and distribution of green spaces, c) quality of green space, and d) characteristics of green space. This study suggests that while there is not a significant relationship, these 
possibilities need to be investigated in the future studies. The author recommends that when investigating the relationship between types of green space, PA, and health, finer resolution of land cover data and exact location of participants would be desirable in order to have better and more accurate results in terms of green space calculation and health benefits of green space.

\section{ACKNOWLEDGEMENTS}

The author would like to thank the Washington State Department of Health for providing the BRFSS data.

\section{REFERENCES}

Akpinar, A., 2014. Assessing the users` perceptions, preferences, and reasons for use of urban greenway in Aydın-Koşuyolu province. Journal of the Faculty of Forestry Istanbul University, 64(2), pp. 41-55.

Akpinar, A., 2015. Landscape Structure and Health Indicators: How Are They Related?. Antalya, Turkey, Landscape Research Society.

Akpinar, A., 2016. How is quality of urban green spaces associated with physical activity and health?. Urban Forestry \& Urban Greening, Vol. 16, p. 76-83.

Akpinar, A., Barbosa-Leiker, C. \& Brooks, K. R., 2016. Does green space matter? Exploring relationships between greenspace type and health indicators. Urban Forestry \& Urban Greening, Vol. 20, p. 407-418.

Akpinar, A. \& Cankurt, M., 2016. How are characteristics of urban green space related to levels of physical activity: Examining the links. Indoor and Built Environment.

Amorim, T. C., Azevedo, M. R. \& Hallal, P. C., 2010. Physical Activity Levels According to Physical and Social Environmental Factors in a Sample of Adults Living in South Brazil. Journal of Physical Activity and Health, 7(Suppl 2), pp. S204-S212.

Barton, J. \& Pretty, J., 2010. What is the best dose of nature and green exercise for improving mental health? A multi-study analysis. Environmental Science \& Technology, Vol. 44, p. 3947-3955.

Bedimo-Rung, A., Mowen, A. J. \& Cohen, D. A., 2005. The significance of parks to physical activity and public health: a conceptual model. Am J Prev Med., 28(2 Suppl 2), pp. 159-68.

Beyer, K. M. M. et al., 2014. Exposure to neighborhood green space and mental health: Evidence from the survey of the health of Wisconsin. Int. J. Environ. Res. Public Health, Vol. 11, pp. 3453-3472.

Bize, R., Johnson, J. A. \& Plotnikoff, R. C., 2007. Physical activity level and health-related quality of life in the general adult population: a systematic review. Prev Med, Vol. 45, pp. 401-15.

CDC, 2006. Behavioral Risk Factor Surveillance System Operational and User's Guide, Atlanta: CDC.

Cohen, D., et. al. 2007. Contribution of public parks to physical activity. American Journal of Public Health, Vol. 97, p. 509-514.
Coombes, E., Jones, A. P. \& Hillsdon, M., 2010. The relationship of physical activity and overweight to objectively measured green space accessibility and use. Social Science \& Medicine, Vol. 70, p. 816-822.

Coon, J. T. et al., 2011. Does Participating in Physical Activity in Outdoor Natural Environments Have a Greater Effect on Physical and Mental Wellbeing than Physical Activity Indoors? A Systematic Review. Environ. Sci. Technol, Vol. 45, p. 17611772 .

De Jong, K. et al., 2012. Perceived green qualities were associated with neighborhood satisfaction, physical activity, and general health: Results from a cross-sectional study in suburban and rural Scania, southern Sweden. Health \& Place, Vol. 18, p. 1374-1380.

de Vries, S., Verheij, R. A., Groenewegen, P. P. \& Preeuwenberg, P. S., 2003. Natural environments- healthy environments? An exploratory analysis of the relationship between greenspace and health. Environment and Planning A., 35(10), pp. 1717-1731.

Dunnett, N., Swanwick, C. \& Woolley, H., 2002. Improving urban parks, play areas and green spaces, London: Department for transport, local government and the regions.

Forman, R. T. T., 2008. Urban regions: Ecology and planning beyond the city. Cambridge: Cambridge University Press.

Fox, K. R., 1999. The influence of physical activity on mental wellbeing. Public Health Nutr, 2(Suppl. 3a), pp. 411-8.

Fry, J. et al., 2011. Completion of the 2006 National Land Cover Database for the Conterminous United States. PE\&RS, 77(9), pp. 858-864.

Go, A. S. et al., 2013. on behalf of the American Heart Association Statistics. Heart disease and stroke statistics-2013 update: a report from the American Heart Association. Circulation, 127(e6-e245).

Hallal, P. C. et al., 2012. Global physical activity levels: surveillance progress, pitfalls, and prospects. Lancet, Vol. 380, p. 247-57.

Hamer, M., Stamatakis, E. \& Steptoe, A., 2009. Dose-response relationship between physical activity and mental health: The Scottish Health Survey. British Journal of Sports Medicine, Vol. 43, p. 1111-1114.

Hansmann, R., Hug, S.-M. \& Seeland, K., 2007. Restoration and stress relief through physical activities in forests and parks. Urban Forestry \& Urban Greening, Vol. 6, pp. 213-225.

Herzog, T. R. \& Strevey, S. J., 2008. Contact with nature, sense of humor, and psychological well-being. Environment and Behavior, 40(6), pp. 747-776.

Jorgensen, A. \& Gobster, P. H., 2010. Shades of Green: Measuring the Ecology of Urban Green Space in the Context of Human Health and Well-Being. Nature and Culture, 5(3), p. 338-363.

Kaczynski, A. T. \& Henderson, K. A., 2007. Environmental Correlates of Physical Activity: A Review of Evidence about Parks and Recreation. Leisure Sciences, 29(4), pp. 315-354. 
Kaczynski, A. T., Potwarka, L. R. \& Saelens, B. E., 2008. Association of park size, distance and features with physical activity in neighborhood parks. American Journal of Public Health, Vol. 98, p. 1451-1456.

Kaczynski, A. T., Potwarka, L. R., Smale, B. J. A. \& Havitz, M. E., 2009. Association of Parkland Proximity with Neighborhood and Park-based Physical Activity: Variations by Gender and Age. Leisure Sciences: An Interdisciplinary Journal, 31(2), pp. 174191.

Kaplan, R., 2001. The Nature of the View from Home: Psychological Benefits. Environment and Behavior, 33(4), pp. 507-542.

Koohsari, M. J. et al., 2015. Public open space, physical activity, urban design and public health: Concepts, methods and research agenda. Health \& Place, Vol. 33, p. 75-82.

Lee, A. C. K. \& Maheswaran, R., 2010. The health benefits of urban green spaces: A review of the evidence. Journal of Public Health, 33(2), p. 212-222.

Lee, I.-M.et al., 2012. Effect of physical inactivity on major noncommunicable diseases worldwide: an analysis of burden of disease and life expectancy. Lancet, 380(9838), p. 219-229.

Lee, S.-W., Ellis, C. D., Kweon, B.-S. \& Hong, S.-K., 2008. Relationship between Landscape Structure and Neighborhood Satisfaction in Urbanized Areas. Landscape and Urban Planning, Vol. 85, p. 60-70.

Maas, J. et al., 2009. Morbidity is related to a green living environment. Journal of Epidemiology and Community Health, 63(12), pp. 967-973.

Maas, J. et al., 2006. Green space, urbanity, and health: how strong is the relation?. J Epidemiol Community Health, Vol. 60, p. $587-592$.

Mackay, G. J. \& Neill, J. T., 2010. The effect of "green exercise" on state anxiety and the role of exercise duration, intensity, and greenness: A quasi-experimental study. Psychology of Sport and Exercise, Vol. 11, pp. 238-245.

Matsuoka, R. H. \& Kaplan, R., 2008. People needs in the urban landscape: Analysis of Landscape and Urban Planning contributions. Landscape and Urban Planning, Vol. 84, p. 7-19.

Mitchell, R., 2013. Is physical activity in natural environments better for mental health than physical activity in other environments?. Social Science \& Medicine, Vol. 91, pp. 130-134.

Sallis, J. F., Floyd, M. F., Rodríguez, D. A. \& Saelens, B. E., 2012. The Role of Built Environments in Physical Activity, Obesity, and CVD. Circulation, 125(5), p. 729-737.

Schipperijn, J. et al., 2013. Associations between physical activity and characteristics of urban green space. Urban Forestry \& Urban Greening, Vol. 12, p. 109-116.

Schipperijn, J. et al., 2010. Factors influencing the use of green space: Results from a Danish national representative survey. Landscape and Urban Planning, Vol. 95, pp. 130-137.
Mokdad, A. H., 2009. The behavioral risk factors surveillance system: Past, present, and future. Annual Review of Public Health, Vol. 30, p. 43-54.

Morita, E. et al., 2007. Psychological effects of forest environments on healthy adults: Shinrin-yoku (forest-air bathing, walking) as a possible method of stress reduction. Journal of the Royal Institute of Public Health, Vol. 121, p. 54-63.

Mowen, A. et al., 2007. The role of park proximity and social support in shaping park visitation, physical activity, and perceived health among older adults. Journal of Physical Activity and Health, Vol. 4, pp. 167-179.

Niemelä, J. et al., 2011. Urban Ecology: Patterns, Processes, and Applications. New York: Oxford University Press.

Nocon, M., Hiemann, T., Muller-Riemenschneider, F. \& Thalau, F., 2008. Association of physical activity with all cause and cardiovascular mortality: a systematic review and meta-analysis. Eur J Cardiovasc Prev Rehabil, Vol. 15, pp. 239-46.

Orr, S., Paskins, J. \& Chaytor, S., 2014. Valuing Urban Green Space: Challenges and Opportunities, London: UCL public policy.

Paquet, C. et al., 2013. Are accessibility and characteristics of public open spaces associated with a better cardiometabolic health?. Landscape and Urban Planning, Vol. 118, p. 70-78.

Picavet, H. S. J. et al., 2016. Greener living environment healthier people? Exploring green space, physical activity and health in the Doetinchem Cohort Study. Preventive Medicine, Vol. 89, pp. 7 14.

Pretty, J. et al., 2007. Green exercise in the UK countryside: Effects on health and psychological well-being, implications for policy and planning. Journal of Environmental Planning and Management, 50(2), pp. 211-231.

Rethorst, C. D., Wipfli, B. M. \& Landers, D. M., 2009. The antidepressive effects of exercise: A meta-analysis of randomized trials. Sports Medicine, Vol. 39, pp. 491-511.

Richardson, E. A. \& Mitchell, R., 2010. Gender differences in relationships between urban green space and health in the United Kingdom. Social Science \& Medicine, Vol. 71, pp. 568-575.

Richardson, E. A., Pearce, J., Mitchell, R. \& Kingham, S., 2013. Role of physical activity in the relationship between urban green space and health. Public Health, Vol. 127, pp. 318-324.

Richardson, E. et al., 2012. Green cities and health: a question of scale?. J Epidemiol Community Health, Vol. 66, pp. 160-165.

Shaw, K., Gennat, H., O’Rourke, P. \& Del Mar, C., 2006. Exercise for overweight or obesity. Cochrane Database Syst Rev, Vol. 4, p. CD003817.

Stigsdotter, U. K. et al., 2010. Health promoting outdoor environments - Associations between green space, and health, health-related quality of life and stress based on a Danish national representative survey. Scandinavian Journal of Public Health, Vol. 38, p. 411-417.

Sugiyama, T. et al., 2010. Associations between recreational walking and attractiveness, size, and proximity of neighborhood open spaces. American Journal of Public Health, 100(9), pp. $1752-7$. 
Tamosiunas, A. et al., 2014. Accessibility and use of urban green spaces, and cardiovascular health: findings from a Kaunas cohort study. Environmental Health, 13(20).

The Ministry of Health, 2014. Physical Activity Guidelines for Turkey, Ankara: The Ministry of Health of Turkey, Public Health Institution, Department of Obesity, Diabetes and Metabolic Diseases.

Toftager, M. et al., 2011. Distance to green space and physical activity: a Danish national representative survey. Journal of Physical Activity and Health, Vol. 8, p. 741-749.

Tsatsoulis, A. \& Fountoulakis, S., 2006. The protective role of exercise on stress system dysregulation and comorbidities. Stress, Obesity, and Metabolic Syndrome, Vol. 1083, p. 196-213.

Ulrich, R. S., 1984. View through a window may influence recovery from surgery. American Association for the Advancement of Science, 224(4647), pp. 420-421.

Ulrich, R. S. et al., 1991. Stress recovery during exposure to natural and urban environments. Journal of Environmental Psychology, Vol. 11, pp. 201-230.

US Department of Health and Human Services, 1996. Physical activity and health: A report of the surge on general, Atlanta, Georgia: US Department of Health and Human Services, Public Health Service, CDC, National Center for Chronic Disease Prevention and Health Promotion.

USGS, 2012. The National Land Cover Database, Sioux Falls: U.S. Geological Survey.

Van den Berg, A. E., Hartig, T. \& Staats, H., 2007. Preference for Nature in Urbanized Societies: Stress, Restoration, and the Pursuit of Sustainability. Journal of Social Issues, 63(1), pp. 79 $-96$.

Van den Berg, A. E. J., Maas, J., Verheij, R. A. \& Groenewegen, P. P., 2010. Green space as a buffer between stressful life events and health. Social Science \& Medicine, Vol. 70, p. 1203-1210.

Van den Berg, A. E., Jorgensen, A. \& Wilson, E. R., 2014. Evaluating restoration in urban green spaces: Does setting type make a difference?. Landscape and Urban Planning, Vol. 127, p. $173-181$.

Warburton, D. E., Nicol, C. W. \& Bredin, S. S., 2006. Health benefits of physical activity: The evidence. CMAJ, 174(6), pp. 801-9.

Ward Thompson, C., 2011. Linking landscape and health: The recurring theme. Landscape and Urban Planning, Vol. 99, pp. 187-195.

Ward Thompson, C. et al., 2012. More green space is linked to less stress in deprived communities: Evidence from salivary cortisol patterns. Landscape and Urban Planning, Vol. 105, p. 221-229.

WHO, 2010. Global recommendations on physical activity for health, Geneva: World Health Organization. 